\title{
Propuesta de Lege Ferenda al tipo penal de trata de personas artículo 367-b del Código Penal salvadoreño
}

\author{
Hazel Jasmín Bolaños Vásquez \\ Investigadora académica de la Universidad Tecnológica de El Salvador \\ Doctora en Derecho con especialidad en Derechos Humanos \\ y Derecho Penal por la Universidad de Zaragoza, España. \\ hazel.bolanos@utec.edu.sv
}

\section{Resumen}

El Salvador penaliza a la trata de personas en el artículo 367-B del Código Penal, el cual, en general, se adecua a las exigencias internacionales, y en especial al Protocolo de Naciones Unidas para prevenir, reprimir y sancionar la trata de personas, especialmente mujeres y niños. Sin embargo, hay ciertos aspectos que deberían tenerse en consideración en una futura reforma, ya que la incompleta configuración y aplicación del tipo penal coadyuvan a la impunidad de los tratantes $y$, consecuentemente, contribuyen a la continuidad y aumento de esta actividad delictiva.

En este sentido, se realizó un estudio del tipo penal salvadoreño utilizando el método de investigación dogmático; haciendo uso de la doctrina penal extranjera y valiéndonos principalmente de la doctrina penal española dada a su influencia y semejanza con el sistema jurídico salvadoreño y los sistemas jurídicos latinoamericanos en general. Como objetivo del estudio se planteó el presentar propuestas concretas de lege ferenda al tipo penal de trata de personas regulado en Código Penal salvadoreño, desde la teoría finalista del delito; con el fin de mejorar la protección de los derechos humanos de las víctimas, a través de la correcta tipificación de la trata de personas.

Como conclusiones del estudio se apuntó la necesidad de hacer reformas concretas al tipo penal en aspectos tales como su ubicación en Código Penal, la referencia a los sujetos activos y la determinación expresa del tipo subjetivo y los medios comisivos del delito.

\section{Palabras clave}

Trata de Personas, Derecho Penal, Teoría del Delito

\begin{abstract}
El Salvador penalizes human trafficking in Article 367-B of the Criminal Code, which generally is adapted to international requirements, and in particular to the United Nations Protocol to Prevent, Suppress and Punish Trafficking in Persons, especially women and children. However, there are certain aspects that should be considered in a future reform, as the incomplete configuration and application of the criminal offense contribute to the impunity of traffickers and, consequently, to the continuation and growth of this criminal activity.

In this sense, the study was conducted on the Salvadoran criminal offense of human trafficking, using the dogmatic research method; through the study of the legal doctrine available, mainly Spanish criminal doctrine, given to its influence and similarity to the Salvadoran legal system and Latin American legal systems in general. The objective of the study is to present concrete proposals of lege ferenda to the criminal offense of human trafficking regulated by the Salvadoran Criminal Code, from the finalist theory of crime; with the aim of improving the protection of human rights of victims, through the correct definition of human trafficking.

As conclusions, the study pointed out the need for specific reforms to the criminal offense in aspects such some elements of Mens rea and Actus reus as its location in the Criminal Code.
\end{abstract}

\section{Keywords}

Human Trafficking, Criminal Law, Theory of Crime 
La trata de personas es un fenómeno muy antiguo que ha acompañado a la humanidad desde tiempos remotos, sin embargo, su visualización y consideración como violación a los derechos humanos y como delito penal ha tomado mayor relevancia en las últimas décadas debido a las nuevas tecnologías y el fenómeno de la globalización. No obstante, a pesar de este reconocimiento en el ámbito internacional, la trata de personas no ha podido ser erradicada dada la dificultad de luchar con los fenómenos sociales y económicos que la propician y que han marcado diferencias entre los países ricos y pobres, generando la migración por motivos económicos con el objeto de conseguir mayores ingresos o un mejor nivel de vida (Maqueda-Abreu, 2002).

A esta penosa situación se ha sumado la formación de redes de criminalidad a nivel internacional que aprovechándose de la situación vulnerable de las personas que viven en los países pobres o subdesarrollados, se dedican a engañar o forzar a personas necesitadas para ser explotadas en diferentes partes del mundo. Este "negocio" genera ingresos multimillonarios a un bajo coste con una mercancía barata y abundante: las personas que viven en extrema pobreza (Pérez-Cepeda, 2006) (2005). Así, miles de personas provenientes de América Latina, el Caribe, África, Asia y Europa del Este son desplazadas de un lugar a otro bajo engaño, violencia o amenaza para luego ser sometidas a la esclavitud o formas análogas a la esclavitud. Esto ha hecho de la trata de personas la actividad global más lucrativa después del tráfico de drogas y de armas (Artola, 2005).

Asimismo, la trata de personas se realiza con distintas finalidades siendo las más frecuentes el trabajo forzado, la servidumbre involuntaria, el pago de deudas, el trabajo infantil, la utilización de menores en conflictos armados, la explotación sexual comercial y el turismo sexual infantil (United States of America, 2012) (2011).

Respecto a la finalidad de trabajo forzado, esta se da cuando se capta a trabajadores para que sean explotados por empleadores inescrupulosos que cuentan con la ventaja de las deficiencias legislativas en el aspecto laboral en los países de origen y/o destino de las víctimas. Los trabajadores son más vulnerables a ser víctimas de trata cuando existen situaciones como el desempleo, la pobreza, la discriminación, la corrupción, los conflictos políticos y la aceptación cultural de esta práctica. Al mismo tiempo, esta finalidad es de las más difíciles de ser identificada y estimada en comparación a otras modalidades debido a varias condiciones como el abuso de contratos, leyes locales inadecuadas respecto al reclutamiento y empleo de trabajadores y la imposición intencional de costos y deudas ilegales a estos trabajadores en el país de origen, frecuentemente con la complicidad y apoyo de las agencias de trabajo y de los empleadores en el país de destino (United States of America, 2012) (2011).

No obstante, las estadísticas presentadas por Naciones Unidas no reflejan que el trabajo forzado sea de las modalidades más frecuentes. Así, en el Informe Global sobre Trata de Personas de 2009 esta modalidad representaba solo un $18 \%$ del total de casos registrados a nivel mundial; mientras que en el Informe Global de 2012 la cantidad de casos reportados de trata de personas para trabajo forzado fue del $36 \%$. El bajo índice de casos de trata con finalidad de trabajo forzado puede deberse tanto a limitaciones históricas así como a la poca legislación en muchos países. (United Nations, 2012) (2009a).

En cuanto a la finalidad de servidumbre involuntaria, la mayoría de sus víctimas son coaccionadas o forzadas tanto física como emocionalmente, llegando incluso al abuso sexual. Los centros de "trabajo" de este tipo de víctimas suelen ser lugares informales y sin conexión con la vida exterior. Este entorno de aislamiento social es propicio para la explotación dado que las autoridades no pueden inspeccionar las propiedades privadas tan fácilmente en comparación a los lugares de trabajo formal (United States of America, 2012) (2011).

Respecto a la finalidad de explotación infantil, en un gran número de situaciones los menores que están bajo la custodia de un miembro ajeno a la familia suelen ser obligados a realizar un trabajo sin que se le ofrezca otra opción. A esta explotación laboral infantil se le aúna la utilización de niños y niñas en conflictos armados que incluye su reclutamiento ilegal por la fuerza, fraude o coacción; para luego ser utilizados en labores de explotación dentro de grupos militares o para ser abusados como esclavos sexuales en las áreas de conflicto. Estas actividades ilegales son perpetradas por fuerzas del gobierno, organizaciones paramilitares o grupos rebeldes (United States of America, 2011) (Maqueda-Abreu, 2003).

Sin embargo, la finalidad más documentada y visible en la actualidad es la explotación sexual, siendo la mayoría de víctimas mujeres y niñas procedentes de zonas geográficas marcadas por la marginalidad y la miseria que son obligadas a prostituirse para pagar una "deuda" en la que supuestamente incurren al haber sido transportadas de un lugar a 
otro. En este sentido, el informe sobre la Trata de Naciones Unidas establece que la modalidad de explotación sexual representa el $58 \%$ de los casos, mientras que el trabajo forzado representa el $36 \%$. Así, en el continente americano se observó que la trata de personas para la explotación sexual fue la más frecuente $21 \%$ seguida del trabajo forzado $44 \%$ siendo raramente detectada otras modalidades. (United Nations, 2012).

Asimismo, son numerosos los casos en los que por razones de pobreza y necesidad, los padres de las víctimas acuerdan contratos de casamiento precoz de sus hijas o las venden a algún tratante sabiendo que serán explotadas sexualmente (United States of America, 2011) (Maqueda-Abreu, 2003). La captación de víctimas se ve favorecida por el uso del Internet, ya que es muy frecuente que los tratantes se anuncien en sitios populares en la red, en los cuales compradores y vendedores pueden conectarse virtualmente para hacer negocios e intercambios. Además, mediante el uso de estas tecnologías también es posible comprar material pornográfico y comunicarse en tiempo real con las víctimas. Numerosos casos similares ocurren con recursos tecnológicos como los celulares, mensajes de texto y otras tecnologías telefónicas (United States of America, 2011).

En cuanto al flujo de la trata de personas existen tres dimensiones: la trata trans-regional, la trata intra-regional y la trata nacional o interna. La trata nacional afecta a las víctimas que son nacionales de un país en el cual son explotadas. La trata intra-regional se da entre diferentes países dentro de la misma región. Esto incluye el cruce de fronteras entre países geográficamente cercanos. La trata trans-regional sucede cuando las víctimas son trasladas de una región a otra. Esta puede ser trata trans-continental, pero también incluye la trata que se da entre regiones vecinas de un mismo continente, como la que se da entre el este de Europa con Oeste y Centro Europa, o entre Centro y Norteamérica (United Nations, 2012).

En este sentido, la mayoría de víctimas de trata son explotadas en un país diferente al de su nacionalidad, siendo la tendencia a tratar víctimas desde áreas pobres hacia áreas ricas, sin que realicen necesariamente traslados de larga distancia, Ilevándose a cabo la mayoría de la actividad transfronteriza entre países de la misma región. Por ejemplo, víctimas de áreas pobres de Centroamérica son tratadas hacia regiones económicamente ricas de Norteamérica o dentro de la misma Centroamérica.
Así, la trata intra-regional fue más frecuente en las fronteras de Centro y Sur América como en las del oeste de África. Sin embargo, respecto a la trata interna resulta relevante remarcar que esta no se da solamente en grandes países, como India y Brasil, en los cuales las dimensiones del país pueden explicar la existencia de trata de personas entre las zonas pobres y las zonas ricas; sino que la trata interna también existe en países relativamente pequeños y ricos, como aquellos que están en Europa. (United Nations, 2012) (2009a).

No obstante, también se documentan casos de trata de personas a largas distancias, siendo Europa el destino con más variedad respecto al origen de las víctimas, contrario al caso de América, el cual es origen y destino de las víctimas de trata. Así, se reportaron casos de traslados a larga distancia de Asia oriental a todas partes del mundo; de África a Europa y América del Norte; de América Latina a América del Norte y Europa; y de Europa y Asia al Oriente Medio. (United Nations, 2012) (2009a).

Por lo que respecta a los tratantes, en la mayoría de los casos estos se acercan a la víctima como una persona de confianza y luego utiliza su conexión con esta para amenazarla con tomar represalias con los miembros de su familia o su entorno cercano si opone resistencia. La mayoría de tratantes son hombres, aunque las mujeres también han tenido un papel clave en este tipo de delincuencia, sobre todo en el Este de Europa, Centro Asia; el Este y Pacífico de Asia, Centroamérica y el Caribe. Así, el informe sobre la Trata de Naciones Unidas reporta que el $30 \%$ de los países la mayoría de estos pertenecientes a Europa informaron que la mayoría de condenados fueron mujeres; en 28 países el porcentaje de mujeres condenadas osciló entre el $10 \mathrm{y}$ el $50 \%$; mientras que el número de mujeres condenadas fue menor al 10\% en 4 países. (United Nations, 2012) (2009a).

Respecto a la nacionalidad de los tratantes, la mayoría son nacionales del país en el que son detenidos, lo que sugiere que las redes delictivas locales reclutan a víctimas nacionales y luego las venden a las redes delictivas de los países de destino. Aun así, existen casos en los que tratantes son extranjeros (United Nations, 2012) (2009a). Mientras que en el caso de las víctimas la mayoría son mujeres y niños. De hecho existen regiones en las que la trata de niños es la única forma de trata detectada. Mientras que la trata de hombres, está más relacionada con la explotación laboral, aunque no es la única finalidad. 
En este sentido, de los países estudiados por el informe de Naciones Unidas sobre la Trata, las dos terceras partes de las víctimas eran mujeres y el $13 \%$ niñas. En el $30 \%$ de los países estudiados, fueron la mayoría de víctimas niños y niñas, En el $42 \%$ de los países los niños y niñas víctimas de trata representaron menos del $10 \%$ de las víctimas; $y$ en el $28 \%$ de los países los niños y niñas víctimas de trata representaron entre el 10 y $50 \%$ del total de víctimas. Respecto a las regiones en las que es más frecuente la trata de niños y niñas se encuentran el Oeste y Centro de África, la subregión Mekong y algunos países de Centro y Sur América. (United Nations, 2012) (2009a).

En el caso concreto de El Salvador, este es un país de origen, tránsito y destino para hombres, mujeres, niños y niñas víctimas de trata con fines de explotación sexual y laboral. La mayoría de víctimas salvadoreñas son mujeres y niñas que provienen del área rural y son llevadas a áreas urbanas para ser explotadas sexualmente; mientras que algunos adultos y menores de edad son explotados en la agricultura, trabajo doméstico y mendicidad. Asimismo, las pandillas salvadoreñas utilizan a menores de edad para la realización de actividades ilícitas (United States of America, 2012). De hecho, según el informe sobre la Trata de Naciones Unidas, El Salvador junto con Colombia y Estados Unidos fueron los países que mostraron un alza en el número de víctimas menores de edad reportadas entre los años 2007-2011. (United Nations, 2012).

En cuanto a las víctimas extranjeras, la mayoría de estas son mujeres, niños y niñas provenientes de países vecinos, principalmente Nicaragua, Guatemala, y Honduras; quienes migran a El Salvador ante falsas ofertas de trabajo que terminan en la explotación de la prostitución ajena, explotación laboral en trabajo doméstico, en la construcción o en el sector informal. De igual forma, existen víctimas salvadoreñas que son tratadas hacia el extranjero con fines de explotación sexual y laboral, principalmente a países como Guatemala, México, Belice, y los Estados Unidos (United Nations, 2012).

Los tratantes son en su mayoría nacionales $97 \%$ viéndose involucrados en algunos casos de trata grupos de crimen organizado (United Nations, 2012) (United States of America, 2012). Contrario a otras regiones en el mundo, el porcentaje de mujeres acusadas por trata de personas $52 \%$ es mayor que el porcentaje de hombres acusados por el mismo delito 48\% (United Nations, 2012).
Respecto a la judicialización de casos, la primera condena por trata de personas en El Salvador fue realizada en el año 2006 cuando cuatro salvadoreños fueron condenados por trata de personas con fines de explotación sexual, mientras que en el año 2007 solo se registró la condena de un hombre por el mismo delito. Las sentencias fueron entre cinco y diez años de prisión (United Nations, 2012). Mientras que en año 2011 se reportó la investigación de 76 casos potenciales de trata de personas y se judicializaron 15 casos, obteniéndose nueve condenas por trata de personas con fines de explotación sexual, cuyas sentencias oscilaron entre los cuatro y nueve años de prisión (United States of America, 2012).

Toda esta situación ha provocado un interés especial a nivel internacional y nacional en regular y penalizar este fenómeno delictivo, así se puede inferir del hecho que en los últimos años la mayoría de países adoptaron medidas legislativas para aplicar el Protocolo contra la trata de personas de Naciones Unidas, el cual es el instrumento internacional más reciente respecto a este delito. Así, anteriormente a la firma de este Protocolo la mayoría de los países no tenían ningún tipo relativo a la trata de personas en sus legislaciones, siendo establecidas la mayoría de estas con posterioridad al 2003. Los primeros países que por primera vez adoptaron legislación anti-trata posterior al Protocolo de Naciones Unidas fueron en su mayoría del Este y Pacífico de Asia, Centroamérica y el Caribe y África del Oeste. (United Nations, 2009a). Así, a agosto de 2012, el 83\% de países estudiados por el informe contra la trata de Naciones Unidas contaba con legislación específica contra este delito en todas o la mayoría de sus modalidades y el $12 \%$ de los países la regulaban de forma parcial. (United States of America, 2012).

No obstante, tampoco podemos obviar que en algunos países y regiones - sobre todo en los países y regiones desarrolladas - se ha abordado la trata de personas como un tema vinculando a la inmigración y a la seguridad (PérezCepeda, 2005). Sin embargo, la mayor dificultad estriba en la mala aplicación del tipo penal que realizan aquellos que aun contando con legislación específica sobre la trata utilizan otras figuras delictivas para perseguirla, debido a las confusiones conceptuales con otros delitos tales como el tráfico o la esclavitud; la confusión de la trata con los delitos concretos de explotación; o la dificultad de probar algunos elementos importantes de la definición como el engaño, o el abuso de condiciones de vulnerabilidad. Todas estas situaciones coadyuvan a la impunidad de los tratantes y consecuentemente contribuyen a la continuidad y aumento de esta actividad delictiva. 
Por esta razón, se hizo necesario estudiar detalladamente los elementos que conforman el tipo penal de trata de personas regulado por el Código Penal salvadoreño, para esto se recurrió al método de investigación dogmático, haciendo uso de la doctrina penal extranjera y valiéndonos principalmente de la doctrina penal española dado su influencia y relevancia en el sistema jurídico salvadoreño y en los sistemas jurídicos latinoamericanos en general. Tras el análisis de cada uno de los elementos del tipo penal desde la teoría finalista del delito se pudieron establecer que aspectos deberían ser añadidos o modificados al artículo 367-B del Código Penal salvadoreño.

\section{Tipo penal}

Existen varias propuestas de regulación jurídico-penal del delito de trata de personas que han sido elaboradas por organismos internacionales, legislaciones internas, organizaciones no gubernamentales y sectores doctrinales. A efecto de nuestro trabajo, estudiaremos principalmente los tipos penales propuestos por el Protocolo para prevenir, reprimir y sancionar la trata de personas, especialmente mujeres y niños de Naciones Unidas y el regulado por el artículo 367-B del Código Penal salvadoreño, haciendo referencia a otras propuestas de tipo penal existentes a modo complementario.

1.1 Tipo penal propuesto por el Protocolo para prevenir, reprimir y sancionar la trata de personas, especialmente mujeres y niños de Naciones Unidas

Este Protocolo establece en su artículo 3 letra a) el tipo penal de trata de personas de la siguiente manera:

“Por 'trata de personas' se entenderá la captación, el transporte, el traslado, la acogida o la recepción de personas, recurriendo a la amenaza o al uso de la fuerza u otras formas de coacción, al rapto, al fraude, al engaño, al abuso de poder o de una situación de vulnerabilidad o a la concesión o recepción de pagos o beneficios para obtener el consentimiento de una persona que tenga autoridad sobre otra, con fines de explotación. Esa explotación incluirá, como mínimo, la explotación de la prostitución ajena u otras formas de explotación sexual, los trabajos o servicios forzados, la esclavitud o las prácticas análogas a la esclavitud, la servidumbre o la extracción de órganos.

En el mismo artículo 3, el mencionado Protocolo añade tres elementos que deben ser tomados en cuenta para la configuración penal del delito, a saber:
1. Que el consentimiento dado por la víctima de la trata de personas a toda forma de explotación intencional descrita en el tipo penal no se tendrá en cuenta cuando se haya recurrido a cualquiera de los medios enunciados en este.

2. Que la captación, el transporte, el traslado, la acogida o la recepción de un niño con fines de explotación se considerará "trata de personas" incluso cuando no se recurra a ninguno de los medios enunciados en el tipo penal.

3. Que por "niño" se entenderá toda persona menor de 18 años.

1.2 Tipo penal propuesto por el Artículo 367-B del Código Penal Salvadoreño

\section{Trata de personas}

Art. 367-B.- El que por sí o como miembro de una organización nacional o internacional con el propósito de obtener un beneficio económico reclute, transporte, traslade, acoja o recepte personas, dentro o fuera del territorio nacional, para ejecutar cualquier actividad de explotación sexual, mantenerlas en trabajos o servicios forzados, en prácticas análogas a la esclavitud, o para extracción de órganos, adopciones fraudulentas o celebración de matrimonios forzados, será sancionado con pena de cuatro a ocho años de prisión.

Todo aquel que facilitare, promoviere o favoreciere cualquiera de las actividades anteriores será sancionado con pena de tres a seis años de prisión.

Cuando las acciones descritas se realizaren en locales comerciales o de cualquier naturaleza que requiera permiso de autoridad competente, ésta deberá revocarlo procediendo al cierre inmediato del mismo.

\section{Agravantes al delito de trata de personas}

Art. 367-C.- El delito al que se refiere el art. 367-B del presente Código, será sancionado con la pena máxima correspondiente aumentada hasta en una tercera parte del máximo e inhabilitación del ejercicio de su profesión durante el tiempo que dure la condena, en los siguientes casos:

1.- Si fuere realizado por funcionarios, empleados públicos y municipales, autoridad pública, agente de autoridad y los agentes de la Policía Nacional Civil.

2.- Cuando la víctima sea menor de dieciocho años de edad o incapaz. 
3.- Si fuere realizado por personas prevaleciéndose de la superioridad originada por relaciones de confianza, doméstica, educativa, de trabajo o cualquier otra relación.

4.- Si como consecuencia de la comisión del delito anterior los sujetos pasivos sufren privaciones de libertad en el extranjero, fueren víctimas de delitos de cualquier orden 0 fallecieren por causas de naturaleza dolosa o culposa.

\section{Bien jurídico protegido}

La determinación del bien jurídico protegido constituye uno de los temas primordiales en la teoría del delito y en el derecho penal contemporáneo, dado que con este se busca proteger los intereses fundamentales de la persona humana y de la sociedad en general; además que por el principio de exclusiva protección de bienes jurídicos, en todo tipo penal debe subyacer un interés elevado a la categoría de bien jurídico, claramente identificado, sin zonas de penumbra, como exigencia irrenunciable del Derecho Penal propio de un Estado Social y Democrático de Derecho. Por lo tanto, para delimitar el bien jurídico protegido por la trata de personas es necesario determinar que conductas tiene la capacidad objetiva para crear el riesgo típicamente relevante para estos derechos, teniendo en cuenta, además, que la determinación del bien jurídico debe ser realizada en clave de derechos humanos (Pérez-Alonso, 2008) (García-Arán, 2006) (2004).

En el ámbito doctrinal se han realizado diferentes aportaciones respecto al bien jurídico protegido por la trata de personas; así, hay quienes consideran que protege la dignidad humana (Villacampa-Estiarte, 2011) (2010) (Juanes-Peces, 2010) (Terradillos-Basoco \& al., 2010), otro sector doctrinal afirma que se protege la integridad moral (Gómez-Navajas, 2007) (Baucells I Lladós, 2006) (Musacchio, 2004) (De LeónVillalba, 2003); o la libertad (Pérez-Alonso, 2008) (TorresFernández, 2006) (Díez-Ripollés, 2004) (Sainz-Cantero-Caparrós, 2002) (Rodríguez-Mesa, 2001). Hay quienes apuestan por considerar que la trata de personas es un delito pluriofensivo (Daunis-Rodríguez, 2011) (Pomares-Cintas, 2011) (Manzanares-Samaniego, 2010) (Terradillos-Basoco, 2010) (Laurenzo-Copello, 2009) (De León-Villalba, 2009) (SánchezCovisa-Villa, 2009) (Martínez-Osorio, 2008) (Alonso-Álamo, 2007).

Incluso existe un sector que afirma que la trata de personas protege un bien jurídico colectivo (Martínez-Osorio, 2008). Sin embargo, huelga aclarar que la mayoría de autores que han tomado esta postura lo han hecho refiriéndose a los delitos contra los derechos de los ciudadanos extranjeros, tal como estaba regulado en el artículo 318 bis, con anterioridad a la reforma del Código Penal español de 2010. Por esta razón se deducía una connotación colectiva del citado delito (Moreno-Torres-Herrera, 2007) (Torres-Fernández, 2006) (Padilla-Alba, 2005) (García-Arán, 2004) (Pérez-Cepeda, 2006) (2004) (Navarro-Cardoso, 2002) (Rodríguez-Montañés, 2001) (Rodríguez-Mesa, 2001).

Mientras que (Terradillos-Basoco \& al., 2010) toman al respecto una postura más ecléctica afirmando que aunque el delito de trata de seres humanos se dirige a la protección de bienes jurídicos personales, también puede apreciarse el carácter colectivo del bien jurídico, junto con la puesta en peligro de otros intereses individuales como la libertad sexual y la explotación laboral. Sin embargo, cualquiera de las posturas que se adopte podemos afirmar que nos encontramos ante un bien jurídico irrenunciable y, por lo tanto, el consentimiento dado por el sujeto pasivo es irrelevante.

En el caso del tipo penal de trata de personas regulado en el artículo 367-B, su ubicación sistemática dentro del Código Penal en el Título de delitos contra la humanidad ha llevado a afirmar que este delito hace referencia -además de los bienes personalísimos de las víctimas- a un bien jurídico supra individual o difuso (Martínez-Osorio, 2008). No obstante, consideramos que la ubicación del delito en el Título de Delitos contra la humanidad junto con el Genocidio, es un error de técnica jurídica, pues la trata de personas -tal y como se regula en el artículo- no cumple con los requisitos de los delitos contra la humanidad.

La regulación de la trata de personas dentro de este título exigiría que su comisión se dé en el marco de un ataque generalizado y sistemático contra una población civil y con conocimiento de este por parte de las autoridades estatales. Además, requiere la concurrencia de una serie determinada de móviles discriminatorios, racistas, xenófobos, etc. De igual forma la consideración de la trata de personas como un crimen contra la humanidad nos llevaría a aseverar que esta protege un bien jurídico colectivo, postura que en nuestra opinión no es compatible con el bien jurídico realmente protegido, que es de carácter individual, porque valoramos que el carácter individual de los derechos protegidos por la trata de personas es evidente, en cuanto en tanto todos estos son derechos personalísimos, por lo tanto, el delito no admite una configuración colectiva. 
Así, en nuestra opinión la trata de personas es un delito pluriofensivo; sin embargo, consideramos que aunque ciertamente esta puede afectar mediatamente a varios derechos, el afirmar la defensa de múltiples bienes jurídicos podría limitar la concreción de las conductas, y dejaría al bien jurídico protegido demasiado en "el aire" o muy generalizado. Consecuentemente, dado a su especial configuración, consideramos que el delito de trata de personas protege a dos bienes jurídicos concretos que se encuentran estrechamente relacionados con la configuración típica de la trata de personas, estos son la integridad moral y la libertad. Comparte esta postura doctrinal (Alonso-Álamo, 2007), pero viendo a la integridad moral como concreción de la dignidad humana.

En primer lugar, porque la integridad moral es un derecho estrechamente vinculado con la libertad de autodeterminación, dado que al doblegarse esta libertad la persona deja de ser tratada como tal para ser considerada como una mera cosa. En segundo lugar, porque en el caso específico del delito de trata de personas, mediante las acciones de captar, trasladar, transportar, acoger y recibir víctimas, mediante medios abusivos como la violencia, la intimidación o incluso el engaño se está atacando claramente a la libertad de la víctima y sus múltiples manifestaciones tales como la libertad individual, de autodeterminación, ambulatoria; conjunto de manifestaciones que se resumen en el status libertatis; $y$ por otra parte, al ejecutar estas acciones con la finalidad de explotar a la víctima se ataca su integridad moral, en tanto en cuanto este acto constituye un trato inhumano y degradante por el cual la víctima es considerada como un cosa.

Por lo tanto consideramos que la trata de personas debería ubicarse dentro del Título III referente a los delitos relativos a la libertad del Código Penal salvadoreño.

\section{Sujeto activo}

El sujeto activo de este delito puede ser cualquier persona física e incluso jurídica, no siendo necesario que reúna una cualidad o condición especial, bastando con que realice la conducta típica; por lo tanto, se trata de un delito común. Sin embargo, en determinadas modalidades típicas cualificantes el delito de trata de personas se convierte en un delito especial, al requerirse que el sujeto activo reúna determinadas cualidades, a saber, la de funcionario, empleado público y municipal, autoridad pública, agente de autoridad o agente de la Policía Nacional Civil.

De la misma forma, el sujeto activo puede realizar uno o varios de los verbos rectores del tipo penal, de forma y con significación alternativa. Sin embargo, en la práctica lo más frecuente es que el sujeto activo no realice solo la conducta puesto que esta manifestación delictiva suele requerir de otros sujetos o coautores para acordar una división de funciones. En este aspecto concuerda la doctrina. Ver por todos (Daunis-Rodríguez, 2011) (Pérez-Alonso, 2008) (LópezCervilla, 2004); (Naciones Unidas, s.f.).

Así, en la práctica la trata de personas es realizada mayormente a través de redes u organizaciones que actúan de forma transnacional y que siguen estructuras jerarquizadas con diferentes niveles de mando, con células operativas individualizadas, con alto grado de autonomía y estructuras más flexibles, heterogéneas en cuanto a la composición de sus miembros, y que en muchos casos son militares de formación y con amplia experiencia en el tráfico de armas, alcohol, tabaco, drogas, falsificación de documentos, y que adaptan sus procedimientos a la trata de personas como negocio (De León-Villalba, 2006); todo esto con la finalidad de facilitar y "rentabilizar" las "ganancias" obtenidas de la ejecución de este delito (Maqueda-Abreu, 2003).

Por esta razón, la legislación salvadoreña se ha dirigido a castigar al sujeto activo que ejecute el delito valiéndose de una organización o asociación de crimen organizado, mostrando así el reproche penal hacia la acción constitutiva de un mayor desvalor de la acción (injusto). En efecto, de ese modo la acción típica adquiere una mayor peligrosidad en la medida en que la utilización de una organización criminal favorecerá la lesión de los bienes jurídicos (Burke, 2008) (Martínez-Osorio, 2008) (Pérez-Alonso, 2008) (López-Cervilla, 2004).

Sin embargo, a pesar que la legislación salvadoreña castiga al sujeto activo que comete el delito dentro de una organización criminal, se incluye en el tipo básico la realización de la conducta típica ya sea por el sujeto activo por sí o como miembro de una organización nacional o internacional, recibiendo en ambos casos la misma pena.

En este sentido, consideramos que el regular en el tipo básico que la conducta típica puede ser realizada ya sea por el sujeto activo por sí o como miembro de una organización nacional o internacional, resta la relevancia penal que tiene el hecho de actuar apoyado en estructuras de crimen organizado; por lo tanto, es necesario que se manifieste la relevancia penal de actuar en el contexto de una organización criminal de manera expresa y con una pena superior.

Asimismo, también es necesario que se regule la responsabilidad de las personas jurídicas respecto a este delito, no 
tanto de carácter penal, sino con carácter administrativo, sobre todo cuando la actividad de trata sea consecuencia de la mala supervisión por parte de los organismos de control de la persona jurídica. Este aspecto actualmente se encuentra impune en la legislación salvadoreña.

\section{Tipo subjetivo}

Por lo que respecta al tipo subjetivo de la trata de personas, podemos afirmar que nos encontramos ante un delito doloso de intención, dado que pertenece al tipo de lo injusto un determinado fin perseguido por el autor (Daunis-Rodríguez, 2011) (Martínez-Osorio, 2008), a saber, el propósito de obtener un beneficio económico. Mientras que (De León-Villalba, 2009) y (Juanes-Peces, 2010) opinan que la perfección del tipo requiere la presencia de un ánimo tendencial.

Por lo tanto, en la trata de personas se exige un dolo específico que consiste en conocer y querer realizar cualquiera de las acciones descritas por los verbos rectores (captar, transportar, trasladar, acoger o recibir) con el fin de explotar al sujeto pasivo en cualquiera de las finalidades reguladas en el tipo penal (Martínez-Osorio, 2008). Sin embargo, no se requiere que el sujeto activo tenga el propósito de explotar por sí mismo a la víctima, bastando con la intención de que el sujeto pasivo sea explotado por él o por un tercero (Daunis-Rodríguez, 2011) (López-Cervilla, 2004). http://es.scribd. com/doc/44842117/Aspectos-Juridicos-Del-Delito-de-Tratade-Personas-en-Colombia

Por lo tanto, dado que la finalidad de explotación del sujeto pasivo es un elemento subjetivo del injusto inherente al concepto típico de trata, es relevante delimitar su significado, dado que su interpretación ha sido considerada problemática (López-Cervilla, 2004).

El tipo penal de trata también hace referencia tanto a la exigencia de la intencionalidad de la acción para tipificarla penalmente; como a la finalidad perseguida con la misma, la cual es la explotación del sujeto pasivo. Sin embargo, para (Pérez-Alonso, 2008), esta exigencia subjetiva le parece superflua e innecesaria si se tiene en cuenta otros elementos esenciales del concepto típico de trata, muy especialmente los medios empleados y la finalidad perseguida; ya que estos elementos evidencian la existencia de un comportamiento plenamente consciente del autor. Similar opinión sostiene (Rebollo-Vargas, 2006).

Asimismo, (Martínez-Osorio, 2008) apunta que esta dualidad presenta una dificultad probatoria dentro del proceso pe- nal. Si bien las situaciones de carácter subjetivo únicamente pueden resultar comprobadas por medio de una construcción hipotética efectuada por medio de las inferencias lógicas derivadas del marco de los hechos objetivos, la situación en el caso de la trata de personas se complica al ser dos los elementos que han de comprobarse, a saber, el propósito de obtener un beneficio económico, para ejecutar cualquier actividad de explotación. Consecuentemente si no resultare plenamente establecido alguno de estos dos elementos, el delito no podría ser aplicado.

Sin embargo, a pesar de que en el tipo penal del CP salvadoreño, contiene -además de las finalidades mínimas reguladas por el Protocolo de Naciones Unidas- a las adopciones fraudulentas y la celebración de matrimonios forzados; resulta difícil imaginar y definir todas las formas de explotación que podrían ser incluidas, además de la dificultad de determinar lo que constituyen prácticas de explotación. A esto se aúna el hecho que, por exigencias del principio de legalidad, se requiere que las formas de explotación se definan clara y taxativamente, consecuentemente, todas las formas de explotación tienen que estar expresamente definidas por la ley penal (United Nations, 2009b).

Como solución a este problema, consideramos que, en primer lugar, las distintas finalidades de explotación que contiene el tipo penal de la trata pretenden evitar que a una persona se la coloque en situación de esclavitud o condición análoga mediante su captación, traslado, transporte acogida o recibimiento. Consiguientemente, al incluir la expresión prácticas análogas a la esclavitud se estaría garantizando que la finalidad de desarrollar todas estas formas de explotación alternativa también resulten incluidas en el tipo penal, sin que esto suponga una interpretación in malam partem. Al margen de ello, sería más conveniente al principio de legalidad que se definiera dentro del precepto legal qué se debe entender por prácticas análogas a la esclavitud, basándose en las definiciones propuestas por los diferentes instrumentos internacionales.

Asimismo, coincidimos con que la explotación debe ser entendida penalmente a los efectos de la trata de personas como la utilización abusiva en provecho propio del trabajo o de las cualidades de otra persona (López-Cervilla, 2004). Este provecho no tiene que ser necesariamente económico, pudiendo ser también un beneficio en especie o el ofrecimiento de una recompensa cualquiera con tal que sea provechosa para el sujeto activo del delito de explotación. 


\section{Medios comisivos}

Los medios regulados por tipo penal propuesto por el Protocolo contra la trata de Naciones Unidas, hace referencia a la amenaza o uso de la fuerza u otras formas de coacción, al rapto, al fraude, al engaño, al abuso de poder o de una situación de vulnerabilidad o a la concesión o recepción de pagos o beneficios para obtener el consentimiento de una persona que tenga autoridad sobre otra.

Sin embargo, el tipo penal regulado por el Código Penal salvadoreño no hace referencia a ninguno de los medios anteriormente mencionados, quizás, porque el legislador salvadoreño consideró que el tratar con una persona es de por sí un delito que debe ser castigado, independientemente de cómo se consiguió el consentimiento de la víctima. Solo regula como agravante el prevalerse de la superioridad originada por relaciones de confianza, doméstica, educativa, de trabajo o cualquier otra relación (art. 367-C). Mientras que (Terradillos-Basoco, 2010) afirma que el actuar en situación de necesidad de la víctima, sin provocarla ni servirse de ella, recurrir a violencias gratuitas o engañar para reforzar un consentimiento previo no integran el tipo de trata de seres humanos.

En este sentido, consideramos que es necesario que en el tipo penal se haga referencia a los medios comisivos regulados por el Protocolo de Naciones Unidas, ya que los medios comisivos son elementos esenciales e inherentes al propio concepto de esta, constituyendo el fundamento de la materia de prohibición penal, en la medida que describen el escenario característico de este fenómeno. Al respecto (Pérez-Alonso, 2008) incluso distingue entre la trata forzada, la trata fraudulenta y la trata abusiva; siendo la trata forzada aquella que exige el empleo de violencia o de intimidación para doblegar la voluntad de la víctima y por lo cual constituye el supuesto más claro y menos problemático; la trata fraudulenta es aquella que se lleva a cabo mediante engaño, el cual es uno de los medios tradicionalmente empleados para conseguir la aceptación o consentimiento de la víctima; y la trata abusiva se refiere al abuso de poder o de una situación de vulnerabilidad o a la concesión o recepción de pagos o beneficios para obtener el consentimiento de una persona que tenga autoridad sobre otra, por lo que posiblemente esta sea la modalidad que mayores problemas de determinación puede plantear por referirse a un medio de contornos más difusos, añadido al hecho de que a veces la situaciones encuadrables en este tipo de trata no son del todo claras y pueden estar muy cerca de los casos de inmigración clandestina.
Asimismo, consideramos que con base en el principio de legalidad, es necesario que se establezca que la trata es un acto realizado contra la voluntad de la víctima, pues al no dejarse claro este aspecto podrían incluirse casos que en sí no constituyen trata de personas sino otros delitos, tal como podría suceder en el caso de los matrimonios que se den a cambio de contraprestaciones, como en la típica dote (tales como casas, inmuebles, ganado, etc.), aclarando que esto no significa que se pueda incurrir en otro tipo de actividad delictiva.

Cabe enfatizar que en el caso de las personas menores de edad o incapaces no será válido el consentimiento dado incluso cuando no hubiesen mediado ninguno de los medios descritos por el tipo. En este sentido, BOLDOVA PASAMAR ET AL afirman que esto supone un tipo alternativo de la trata de personas, por cuanto solo requiere que se realice la acción típica unido a la finalidad de explotación de la persona, sin necesidad de la concurrencia de medio específico alguno para lograr la captación o control sobre la persona, que en este caso debe ser menor de edad (Boldova-Pasamar \& al., 2010).

\section{Referencias}

Alonso-Álamo, M. (2007). ¿Protección penal de la dignidad? A propósito de los delitos relativos a la prostitución y a la trata de personas para la explotación sexual. Revista penal(19), 3-20.

Artola, J. (2005). El caso de la trata de personas. . (OIM, Ed.) Recuperado el 8 de enero de 2013, de Programas del Instituto Mexicano de Radio: <http:// www.blogs.imer.gob.mx/arreglandoelmundo/files/2010/07/caso-de-la-trata-de-personas.pdf>

Baucells I Lladós, J. (2006). El tráfico ilegal de personas para su explotación sexual . En R. Rodríguez, R. Mesa, \& (Coords.), Inmigración y sistema penal: retos y desafíos para el siglo XXI (págs. 173-202). Valencia: Tirant lo Blanch.

Boldova-Pasamar, M. Á., \& al., e. (2010). Trata de menores. Aspectos jurídicos, perspectivas de derecho comparado y propuestas de lege ferenda en relación con el marco normativo español. Madrid: Ministerio de Sanidad y Política Social. 
Burke, C. (2008). Smuggling versus Trafficking: Do the U.N. Protocols have it right? (U. o. Denver, Ed.) Human Rights \& Human Welfare, Topical Research Digest: Human Rights and Human Trafficking, 104-119.

Daunis-Rodríguez, A. (2011). El tráfico y la trata de personas tras la reforma del Código Penal. En Z. Rodríguez, G. Barranco, F. García, \& (Coords.), La reforma penal de 2010 (págs. 121-137). Salamanca: Ratio Legis.

De León-Villalba, F. J. (2003). Tráfico de personas e inmigración ilegal. Valencia: Tirant lo Blanch.

De León-Villalba, F. J. (2006). Inmigración llegal y Tráfico de seres humanos. En A. Zapatero, N. Martín, \& (Dirs.), La Orden de Detención y Entrega Europea. (págs. 161-171). Cuenca: Ediciones de la Universidad de Castilla-La Mancha.

De León-Villalba, F. J. (2009). Propuesta de reforma frente a la trata de seres humanos. En C. Sanz, \& e. al., El anteproyecto de modificación del Código Penal de 2008: algunos aspectos (págs. 125-150). Bilbao: Universidad de Deusto.

Díez-Ripollés, J. L. (2004). Delitos contra la libertad e indemnidad sexuales. En R. Casabona, D. Ripollés, \& (Coords.), Comentarios al Código Penal. Parte Especial II. Títulos VII-XII y faltas correspondientes (págs. 209-269). Valencia: Tirant lo blanch.

García-Arán, M. (2004). Esclavitud y tráfico de seres humanos. En Estudios penales en recuerdo del profesor Ruiz Antón (págs. 355-378.). Valencia: Tirant lo blanch.

García-Arán, M. (2006). Trata de Personas y Explotación Sexual. García Aran. Granada: Comares.

Gómez-Navajas, J. (2007). Inmigración ilegal y delincuencia organizada. En Z. Espinar, \& (Dtor.), El derecho penal ante el fenómeno de la inmigración (págs. 387-462). Valencia: Tirant lo blanch.

Juanes-Peces, Á. (2010). El delito de trata de seres humano en el proyecto de reforma del Código Penal de 1995. Actualidad Jurídica, Año XIX(803), 1-6.

Laurenzo-Copello, P. (2009). El modelo de protección penal de los inmigrantes: de víctimas a excluidos. En C. Mateu, G. Cussac, O. Berenguer, \& (Dirs.), Constitución, Derechos Fundamentales y Sistema Penal (Vol. Tomo II, págs. 1149-1171). Valencia: Tirant lo Blanch.
López-Cervilla, J. M. (2004). El extranjero como víctima del delito. Análisis de los tipos penales. (M. d. Justicia., Ed.) Estudios Jurídicos, 2636-2836.

Manzanares-Samaniego, J. L. (2010). Código Penal (Comentarios y jurisprudencia) Parte Especial (Vol. II). Granada: Comares.

Maqueda-Abreu, M. L. (2002). La trata sexual de mujeres extranjeras: Una aproximación jurisprudencial. Revista de la Facultad de Derecho de la Universidad de Granada.(5), 439-448.

Maqueda-Abreu, M. L. (2003). El comercio sexual de seres humanos: una esclavitud de todos los tiempos. En O. Berenguer, \& (Coord.), Prostitución y derecho en el cine (págs. 59-72). Valencia: Tirant lo blanch.

Martínez-Osorio, M. A. (2008). El delito de trata de personas en el Código Penal Salvadoreño. San Salvador: Consejo Nacional de la Judicatura.

Moreno-Torres-Herrera, M. R. (2007). La protección penal del menor extranjero. En Z. Espinar, \& (Dtor.), El derecho penal ante el fenómeno de la inmigración. (págs. 463-483). Valencia: Tirant lo Blanch.

Musacchio, V. (2004). Migration, Prostitution and Trafficking in Women: An Overview. German Law Journal, 05(09), 1015-1030.

Naciones Unidas. (s.f.). Niños, niñas y adolescentes víctimas de delitos de trata de personas y explotación sexual/laboral. Bogotá: Oficina de las Naciones Unidas contra la Droga y el Delito.

Navarro-Cardoso, F. (2002). Observaciones sobre los delitos contra los derechos de los ciudadanos extranjeros. Revista Penal(10).

Padilla-Alba, H. R. (2005). )El delito de tráfico ilegal de personas tras su reforma por la LO 11/2003, de 29 de septiembre. La Ley Penal(14), 5-23.

Pérez-Alonso, E. J. (2008). Tráfico de personas e inmigración clandestina. , . págs. Valencia: Tirant lo Blanch.

Pérez-Cepeda, A. I. (2005). El tráfico de mujeres con el fin de la explotación sexual. En J. Giró, El género quebrantado. Sobre la violencia, la libertad y los derechos de la mujer en el nuevo milenio. (págs. 85-124). Madrid: Catarata.

Pérez-Cepeda, A. I. (2006). Delitos contra los derechos de los ciudadanos extranjeros (Art. 318 bis Reforma- 
do por LO 11/2004). En R. Rodríguez, R. Mesa, \& (Coords.), Inmigración y sistema penal: retos y desafíos para el siglo XXI. (págs. 109-171.). Valencia: Tirant lo Blanch.

Pomares-Cintas, E. (2011). Trata de personas. En Q. Olivares, C. Mateu, M. Prats, G. Rivas, Á. García, \& (Dirs.), Esquemas de la parte especial del Derecho Penal (I) (Vol. XXXII, págs. 131-144). Valencia: Tirant lo Blanch.

Rebollo-Vargas, R. (2006). Normativa Internacional y Derecho Comparado. En G. A. (Coord.), Trata de personas y explotación sexual. Granada: Comares.

Rodríguez-Mesa, M. J. (2001). Delitos contra los derechos de los ciudadanos extranjeros. Valencia: Tirant lo blanch.

Rodríguez-Montañés, T. (2001). Ley de Extranjería y Derecho Penal.,. Diario La Ley(2).

Sainz-Cantero-Caparrós, J. E. (2002). Los delitos contra los derechos de los ciudadanos extranjeros. Barcelona: Atelier.

Sánchez-Covisa-Villa, J. (2009). La trata de seres humanos y el favorecimiento de la inmigración clandestina en el Derecho Penal Español. Justificación de la futura reforma del Código Penal. Análisis sistemático de la jurisprudencia de la Sala Segunda del Tribunal Supremo. Seminario permanente sobre migraciones internacionales y extranjería. (pág. 106). Zaragoza.: Intermigra.
Terradillos-Basoco, J. M. (2010). Trata de seres humanos. En Á. García, G. Cussac, \& (Dirs), Comentarios a la reforma penal de 2010 (págs. 207-217). Valencia: Tirant lo Blanch.

Terradillos-Basoco, J. M., \& al., e. (2010). Trata de seres humanos: Art. 177 bis CP. En Á. García, \& G. C. (Directores), Consideraciones a propósito del Proyecto de Ley de 2009 de modificación del Código Penal (págs. 193-202). Valencia: Tirant lo Blanch.

Torres-Fernández, M. E. (2006). El tráfico de personas con fines de inmigración ilegal del artículo 318 bis del Código Penal. Diario La Ley(6491), 25.

United Nations. (2009a). Global Report on Trafficking in Persons. Viena: Office on Drugs and Crime.

United Nations. (2009b). Model Law against Trafficking in Persons. Viena: Office on Drugs and Crime.

United Nations. (2012). Global Report on Trafficking in Persons. Viena: Office on Drugs and Crime.

United Natios. (s.f.).

United States of America. (2011). Trafficking in Persons Report. . Department of State.

United States of America. (2012). Trafficking in Persons Report. págs. . Department of State.

Villacampa-Estiarte, C. (2011). El Delito de Trata de Seres Humanos. Una incriminación Dictada desde el Derecho Internacional. Navarra: Thomson Reuters Aranzadi. 